\title{
A Carta Miemeyer de 1846 e as condições de leitura dos produtos cartográficos
}

Renato Amado Peixoto*

Resumo. A Carta Niemeyer de 1846 foi a primeira Carta Geral do Brasil e, por meio desta, pretendemos discorrer sobre o emprego e as condições de leitura dos produtos cartográficos pelos historiadores, procurando, ao mesmo tempo, demarcar tanto seus limites quanto suas possibilidades.

Palavras-chave: Carta Niemeyer (1846). Produtos cartográficos.

Este artigo é um pequeno estudo acerca da Carta Niemeyer de 1846, a primeira Carta Geral brasileira produzida no século XIX, a qual se insere no esforço de construção historiográfica do espaço nacional, incorporada que foi a um projeto de nação construído em

*Renato Amado Peixoto é Doutor em História Social pela UFRJ.

Anos 90, Porto Alegre, v. 11, n. 19/20, p.299-318, jan./dez. 2004 
A Carta Niemeyer de 1846 e as condições de leitura...

torno do Instituto Histórico e Geográfico Brasileiro - IHGB. ${ }^{1}$ Utilizando tal enfoque, pretendemos discorrer sobre o emprego e as condições de leitura dos produtos cartográficos pelos historiadores, procurando, ao mesmo tempo, demarcar tanto seus limites quanto suas possibilidades.

J. B. Harley foi o único autor a propor uma leitura dos produtos cartográficos capaz de ultrapassar os métodos e a interpretação costumeira dos historiadores da cartografia, que visavam, segundo esse autor, apenas investigar e catalogar os mapas segundo suas características técnicas e de produção. Tal atitude, segundo Harley, refletiria a adesão de seus cultores a um "positivismo cartográfico" que deveria ser confrontado e substituído por uma interpretação baseada, por sua vez, numa teoria iconológica e semiológica da natureza dos mapas (Harley, 2001a, 2001b). Para esse fim, Harley proporia a utilização dos conceitos anteriormente desenvolvidos por Erwin Panofsky (1976) para o estudo dos níveis dos temas ou significados na arte, visando, com estes, identificar através dos elementos simbólicos e estruturais dos mapas certas disposições qualificadas como "eminentemente retóricas", as quais seriam capazes de explicitar relações de "Poder e Saber", conforme a definição foucaultiana, bem como certos condicionamentos sociais. ${ }^{2}$

Ainda que reconheçamos a pertinência da teorização de Harley, acreditamos que, por conta da grande abertura e universalidade de seus conceitos, esta deva ter seu uso condicionado a análises e enfoques que, por sua vez, devam estar orientados e direcionados por um método que permita perscrutar o símbolo a partir de uma pesquisa do contexto que envolve a composição cartográfica, entendida aqui como um ato da representação que objetiva a Vontade de certos indivíduos ou grupos. Em nosso entender, esse ato de representação está conectado a propósitos, conveniências e circunstâncias que, para serem alcançados, demandariam tanto a constituição de certas mecânicas de produção, quanto a consecução de certos processos de escolha, cuja compreensão permitiria a leitura dos significados dos elementos e das estruturas técnicas do mapa como participantes de um processo criativo, a composição

Anos 90, Porto Alegre, v. 11, n. 19/20, p.299-318, jan./dez. 2004 
cartográfica, uma vez que sua efetivação está conectada diretamente à objetivação do ato de representação. Portanto, o estudo da composição do mapa pode ser tão ou mais significante quanto a interpretação do mapa em si. ${ }^{3}$ Esse método permite também trabalharem-se os textos referentes ao esforço da composição cartográfica relacionando-os com seus próprios produtos, o que possibilita leituras que não estão diretamente relacionadas com a utilização do mapa ou com os efeitos de sua divulgação, mas com um contexto partilhado pelas dinâmicas da mecânica de produção ou pelos processos de escolha, o que possibilita ao historiador, por exemplo, inferir a episteme relativa a um determinado período, grupo ou lugar, objetivo também perseguido por Harley (2001d, p.8788), ainda que mais pontualmente.

Finalmente, em relação às intenções restritas deste estudo, faltanos definir, utilizando os argumentos anteriores, que, se o mesmo ato de representação está relacionado a determinados propósitos, conveniências e circunstâncias, insertos em determinada condição, esse ato objetiva-se através da competição ou pelo ajustamento a outros atos também objetivados pela motivação, o que, por sua vez, leva a estabelecer, para o historiador, novos lugares para a leitura de contextos e referências (v. Schopenhauer, 2001, \56-57, 2003, cap. 2).

A partir de Schopenhauer, podemos compreender essa objetivação da Vontade como uma disputa entre os indivíduos que visam expressar suas Idéias por meio de sua materialização. Contudo, como essa matéria será disputada com o mesmo fim por outros indivíduos, todos tenderão continuamente a usurpá-la, possuindoa, cada um deles, apenas na medida do que puderam tomar dos outros: constituir-se-á assim, em torno do ato de representação, uma guerra eterna de vida ou de morte, quando o surgimento de obstáculos e impedimentos à objetivação da Vontade se consubstanciará no indivíduo através do sofrimento e da insatisfação. Portanto, o ato de representação dá-se em meio a um competição contínua pela expressão da Idéia, interessando e emocionando a Vontade, daí relacionar-se pela sua satisfação com determinados

Anos 90, Porto Alegre, v. 11, n. 19/20, p.299-318, jan./dez. 2004 
A Carta Niemeyer de 1846 e as condições de leitura...

propósitos, conveniências, eventos e circunstâncias. Por conseguinte, esse mesmo ato da vontade será objetivado ainda que ao custo de sua transformação e do seu ajustamento a outros atos da vontade inclusive alheios e vinculados a outras motivações, não sem lançar o indivíduo novamente no sofrimento e na insatisfação que, por sua vez, o conduzirão a novos atos de vontade, no estado que denominamos de luta de representações (v. Schopenhauer, 2001, \ 56-57, 2003, cap. 2).

\section{A cartografia do século XIX e sua leitura}

O estudo da Carta Niemeyer de 1846 será constituído sobre o método anterior, mas utilizando a premissa, a qual a exiguidade deste trabalho não nos permite desenvolver, de que o esforço da construção do Estado nacional e da produção de sua representação cartográfica valeu-se do material e da estrutura dos produtos cartográficos anteriores, adaptando-os à narração de seu próprio passado e em prol de seus objetivos, visando assim estabelecer uma legitimidade narrativa, por meio da qual o espaço foi sucessivamente apagado e reescrito em torno de um novo eixo de sintaxe: a Ordem e a Civilização (v. Peixoto, 2003, 2005). Ainda é necessário explicar que, durante os séculos XVII e XVIII, a cartografia constituiu-se numa escrita coletiva por excelência, dotada de práticas diversas e complexas, tornando necessário que a leitura do processo de composição dos mapas seja feito através da apreensão de estratégias e táticas que incluem tanto o agenciamento das técnicas e das condições da escrita, quanto a distribuição e atribuição de tarefas. Por conta dessas características, a cartografia tornou-se o lugar por excelência de inscrição da narração territorial, o que nos leva a ter que analisar também os processos de escolha, produção, reprodução e divulgação da cartografia, ou seja, investigar a socialidade dessa escrita tendo em vista que seu sujeito é também um sistema de relações entre seus diversos estratos, compostos pela recepção, compreensão, interação e transformação, o que denominaremos de teatro da narrativa. ${ }^{4}$ Nesse sentido, entendemos ser necessário distinguir, na

Anos 90, Porto Alegre, v. 11, n. 19/20, p.299-318, jan./dez. 2004 


\section{Renato Amado Peixoto}

leitura dos mapas, a existência simultânea de dois processos, um externo, relativo às relações com as Instituições e o Estado, e outro interno, que diz respeito à natureza das práticas e procedimentos cartográficos, ou seja, das classificações, generalizações, hierarquizações, divisões de trabalho e formalização das decisões.

Esses dois processos simultâneos distinguir-se-iam do que Harley definiu como poder interno e poder externo, entendidos por esse autor como a contraposição de uma instância de poder local e descentralizado a uma outra, centralizada e concentrada. Para Harley, a convivência entre essas duas instâncias faria parte das relações de poder que penetrariam os interstícios da prática e da representação cartográfica, permitindo assim com que os mapas pudessem ser lidos como textos que legitimariam a teorização Poder-Saber de Foucault (Harley, 2001c, p.111-113). Contudo, entendemos em nossa idéia de processo interno e processo externo, anteriormente expressada, que, além das relações apontadas por Harley, a construção da representação esteja sujeita ainda a ser modificada, alterada ou limitada por circunstâncias inerentes às propriedades e características das técnicas e procedimentos, devendo-se estender ainda essa impressão às leituras daí resultantes. Nesse sentido, deve-se salientar que o agenciamento das técnicas faz parte de um processo de escolhas que não é apenas subjetivo, mas que também constitui-se num procedimento da representação da forma, ligado às estratégias e táticas dos operadores das representações. Estas, por sua vez, estão sujeitas ainda às capacidades técnicas ou operacionais dos últimos e mesmo às finalidades da representação.

No caso da apropriação da cartografia por parte da historiografia dos séculos XIX e XX, adiantaremos que as finalidades operacionais da narrativa ultrapassaram os procedimentos técnicos dos mapas, fazendo com que o agenciamento das técnicas tornassese um medium para a entrada em cena do objeto no mundo da representação. Assim, esse medium agenciado no esforço da representação do espaço nacional constituiu, ele mesmo, parte dessa operação, transformando a objetivação da representação do espaço esboçada através do debate realizado no teatro da narrativa, ou,

Anos 90, Porto Alegre, v. 11, n. 19/20, p.299-318, jan./dez. 2004 
A Carta Niemeyer de 1846 e as condições de leitura...

utilizando a comparação da Retórica com a representação feita por Schopenhauer, o medium pode constituir o objeto através de uma "dissimulação" de sua forma, uma vez que o objeto é a representação do sujeito mesmo (v. Schopenhauer, 2001, \ 47, 2003, p.48-49).

Em nossa idéia de processo externo e processo interno, contudo, o medium, seja este uma técnica, seja a Retórica, primeiramente é entendido como condicionado, na medida em que, através do processo externo, a expressão da Idéia compreendeu objeto e sujeito de maneira igual. Em segundo lugar, o medium também é entendido como condicionante, ao certas características do processo interno, seja sua constituição autônoma, sejam suas limitações técnicas, imporem, à expressão da Idéia do processo externo, restrições à sua representação pura, constituindo-a como uma objetividade imperfeita da Vontade, e que, em tese, devesse ser complementada ou substituída por outras representações.

Finalmente em relação ao medium, e novamente remetendo ao caso da apropriação historiográfica da cartografia, se as táticas ou estratégias dos operadores exigirem um sacrifício intencional da forma, ou seja, se as finalidades operacionais ultrapassarem as condições técnicas, pode produzir-se, através do medium, uma alteração do objeto não prevista pelos operadores, constituindo-se essa alteração do objeto, ela mesma, como uma representação mais ou menos independente da objetivação da Vontade, ou no caso, do espaço em produção. Assim, o medium é entendido, em nosso método, como um facilitador da apreensão da Idéia pelos outros, e essa apreensão da Idéia será condicionada pela natureza ou característica do medium e pelo gênio do operador. ${ }^{5}$

Em respeito à importância do medium para a representação, podemos citar o adendo de Schopenhauer à célebre discussão sobre a razão de não se representar o grito do personagem ferido no grupo escultural de Laocoonte. Enquanto Winckelmann e Lessing atribuíram tal característica, respectivamente, ao estoicismo do personagem ou à incompatibilidade da beleza com a dor, para Schopenhauer a ação de gritar não fora representada "pela simples razão de que o grito é inteiramente rebelde aos meios de imitação

Anos 90, Porto Alegre, v. 11, n. 19/20, p.299-318, jan./dez. 2004 


\section{Renato Amado Peixoto}

da escultura". Portanto, para Schopenhauer, era impossível tirar do mármore um Laocoonte a gritar, entendendo, assim, existirem limites para a representação, os quais estariam impressos nas possibilidades mesmas do medium (Schopenhauer, 2001, \46). Portanto, ainda que a apropriação da cartografia pela narrativa historiográfica fosse determinada pela disponibilidade dos objetos cartográficos e derivasse, sobretudo, do esforço do Estado, a inscrição da representação do espaço nacional fez-se no cruzamento de diferentes processos externos e processos internos, com suas dissimulações e alterações, proporcionando distintas leituras do espaço nacional. Estas, por sua vez, ocasionaram a subseqüente necessidade de os operadores da narrativa fazê-las convergir para uma norma da representação cartográfica, a qual se consubstanciaria nas iniciativas visando à composição de uma Carta Geral brasileira.

\section{O medium cartográfico nos séculos XVII e XVIII}

Até o século XIX, o método usual para a reprodução de mapas e de atlas era o da gravação em cobre: os mapas manuscritos tinham seus detalhes copiados para uma placa desse material, na qual eram gravados em alto-relevo, gerando-se assim uma matriz de impressão passível de receber alterações e capaz de permitir seguidas reimpressões. Nesse sentido, estima-se que uma matriz de cobre bem cuidada e que recebesse uma manutenção regular do traçado de seu relevo podia ser utilizada até três mil vezes, possuindo comumente uma durabilidade capaz de ultrapassar a centena de anos (Verner, 1975, p.72). Entretanto, a gravação em cobre era um processo caro, trabalhoso e altamente especializado e, por conta dessas características, o processo cartográfico consolidou-se, nos séculos XVII e XVIII, apenas onde o Estado fosse capaz de arcar com seus custos ou onde existisse um mercado capaz de atrair empreen-dimentos particulares que possibilitassem, sobretudo, a manutenção dos melhores profissionais.

Nesse período, foi estabelecida uma nova tradição no processo cartográfico, com uma separação e uma estandardização rigorosa

Anos 90, Porto Alegre, v. 11, n. 19/20, p.299-318, jan./dez. 2004 
A Carta Niemeyer de 1846 e as condições de leitura...

das tarefas entre astrônomos, desenhistas, gravadores e impressores, o que consolidou o controle do processo interno nas mãos dos editores (o que pode ser exemplificado, inclusive, através da prevalência do anonimato no processo cartográfico) (Harley, 2001c, p.113-115). Contudo, alguns cartógrafos, como Gerhard Mercator, John Thornton e John Arrowsmith foram capazes de dominar todos as instâncias do processo cartográfico, estabelecendo-se privativamente e disputando o mercado de mapas e atlas com trabalhos de sua autoria (Verner, 1975, p.70). Portanto, uma das principais características da cartografia anterior ao século XIX é a existência de diferentes centros fora do controle direto do processo externo, capazes de produzir em escala e em disputa pelo controle de um mercado, em busca de uma lucratividade que se devia ao fato de os produtos cartográficos não serem apenas utilizados como fonte de informação para o Estado ou para o investidor, mas também como estímulos de sociabilidade e artigos de uma cultura de consumo que se estabeleceram no período. Tais eventos foram impulsionados pelas transformações culturais decorrentes da difusão da tipografia e das notícias das viagens transatlânticas, popularizadas pelas corografias e narrações dos viajantes (v. Mukerji, 1983a, 1983b, p.30-130).

O desenvolvimento da gravação em cobre foi decisivo para o estabelecimento das condições desse novo mercado, propiciando que a cartografia se tornasse, durante o século XIX, parte mesmo da cultura material, com seus produtos circulando sob as mais variadas formas, tanto como atlas e mapas de diversos tamanhos, quanto como elemento decorativo em utensílios e vestimentas. Contudo, essa popularização dos produtos cartográficos e corográficos, que compunham uma cultura de elites até o século XVIII, somente se tornou possível pela apropriação, nas estratégias dos processos internos, de uma nova técnica desenvolvida e divulgada nas primeiras décadas do século XIX: a litografia. 


\section{A litografia e a cartografia no Brasil}

A técnica litográfica consistia na escrita direta sobre uma matriz de pedra calcária ou zinco ou no transporte dessa escrita para a pedra através de uma folha especial, quando então se utilizava um processo químico que tornava a superfície capaz de permitir sucessivas impressões. Além de tornar a composição dos mapas mais rápida, pois exigia uma menor especialização de tarefas, ao eliminar, por exemplo, a obrigação de que esses fossem desenhados em reverso como na gravação em cobre, a litografia também possibilitou uma diminuição acentuada dos custos materiais na cartografia. Essas características tornaram possível, no século XIX, disponibilizaremse os produtos cartográficos a um público imensamente maior e mais diversificado que nos séculos anteriores, ao mesmo tempo em que permitiriam que países sem tradição de produção cartográfica em escala, como era o caso de Portugal e depois do Brasil, pudessem desenvolver uma incipiente produção cartográfica em escala.

A criação do Arquivo Militar, já no mesmo ano da chegada da Corte ao Brasil, serve para aferir a existência de uma percepção, no bojo da transferência do Estado português, de que a produção cartográfica em escala poderia coadjuvar a ação do Estado, trazendo vantagens administrativas e servindo como um instrumento prático para a centralização da autoridade. Nesse sentido, essa instituição teria a função de centralizar a guarda, a organização e a classificação dos produtos cartográficos, para que fosse possível então, utilizandose os critérios da utilidade e da necessidade administrativa, escolherse o material a ser vulgarizado.

O principal objetivo dessa iniciativa foi o de recolher todos as cartas, os mapas topográficos e os planos iconográficos trazidos de Portugal para que fossem juntados aos que se encontravam dispersos no Brasil entre várias repartições, acabando-se assim com a descentralização documental que imperava até então nas secretarias de Estado portuguesas. Entretanto, essa primeira iniciativa de centralização cartográfica no Brasil estaria dada ao fracasso por dois motivos. Primeiro, porque a antiga tradição de descentralização seria

Anos 90, Porto Alegre, v. 11, n. 19/20, p.299-318, jan./dez. 2004 
A Carta Niemeyer de 1846 e as condições de leitura...

paulatinamente retomada, sendo que, durante o Segundo Reinado, se constituiriam outros dois grandes arquivos cartográficos ao lado do Arquivo Militar, um na Secretaria de Estrangeiros e outro na de Obras Públicas. Em segundo lugar, grande parte da documentação que fora reunida no Arquivo Militar retornou a Portugal junto com D. João VI em 1821, sem que se distinguisse critério algum nesse repatriamento, o que tanto acarretou a permanência no Brasil de muitos produtos cartográficos relativos a Portugal e seus domínios, quanto a ida para Portugal de muito do que fora produzido sobre o Brasil. Esse problema somente seria sanado em 1867 com uma permuta documental efetuada pela Comissão Investigadora de Mapas e Memórias Concernentes ao Brasil, negociada e acompanhada em Portugal diretamente por Duarte da Ponte Ribeiro, que também foi o responsável pela seleção desses documentos nos arquivos dos dois países.

Embora se pensasse, quando da criação do Arquivo Militar, em utilizar a gravação em cobre na produção cartográfica em escala, as vantagens da litografia tornar-se-iam óbvias, tanto para o Estado português quanto para seu sucessor, a partir da divulgação dessa técnica no final da segunda década do século XIX. Essa opção consolidou-se na prática com a criação, em 1825, da Oficina Litográfica do Exército, quando se importaria todo o material necessário à sua operação junto com dois técnicos estrangeiros responsáveis por sua utilização, os quais deveriam atuar também como professores junto a um corpo de aprendizes composto por soldados do Exército.

Ainda que, com essas iniciativas, o Estado buscasse resguardar para si o controle da vulgarização dos mapas, não foi possível consolidar, junto ao processo externo, a centralização da produção cartográfica, uma vez que, em Portugal, esse processo não havia se transformado em consonância com as mudanças no processo interno que acompanharam o desenvolvimento da reprodução em escala na Europa nos séculos anteriores, ou seja, através de uma especialização e uma estandardização das tarefas cartográficas. Nesse sentido, preservaram-se, no Brasil, as condições tecnológicas e culturais

Anos 90, Porto Alegre, v. 11, n. 19/20, p.299-318, jan./dez. 2004 


\section{Renato Amado Peixoto}

herdadas de Portugal, as quais impuseram, ao processo de produção, a composição cartográfica manuscrita, com suas características de individualização, concentração em setores determinados, sigilo e repetição de padrões, em que cada cartógrafo era, acima de tudo, o membro de uma escola e um transmissor de padrões estabelecidos. ${ }^{5}$ Em conseqüência, a parte mais representativa da produção cartográfica em escala no Brasil durante o século XIX ou foi uma reprodução direta do manuscrito, ou foi uma composição sob as técnicas da reprodução manuscrita, ou seja, submeteu-se o medium litográfico às regras, às limitações e aos condicionamentos culturais do medium manuscrito.

Por outro lado, o controle do processo interno da produção cartográfica pelo processo externo seria dificultado pela constante defecção dos quadros da Oficina para a atividade privada, uma vez que o custo e a adaptabilidade da técnica litográfica a outras tarefas tornavam esse ofício muito lucrativo. Mesmo assim, alguns poucos profissionais bastante qualificados fizeram parte dos quadros da Oficina, como Pedro Torquato Xavier de Brito, autor da redução da Carta do Império de 1856 e Carlos Abeleé, que produziu a Coleção dos figurinos dos uniformes dos corpos do Exército, significativa como demonstração do controle, pela Oficina, da técnica de impressão litográfica em cores, a chamada cromolitografia (Brito, s./d., 1870). Embora criticados, esses profissionais seriam responsáveis pelas reproduções litográficas de bom nível técnico, como, por exemplo, as cartas dos rios Uruguai, Içá e Javari e os mapas provinciais do Rio Grande do Sul, Santa Catarina, Rio de Janeiro, Mato Grosso, Sergipe, Piauí, Ceará, Espírito Santo, Minas Gerais, Maranhão e Paraná.

Cabe salientar, entretanto, algumas cifras em relação à Oficina: em primeiro lugar, os mapas e cartas compuseram apenas uma parte muito restrita de sua produção, uma vez que somente cerca de 3\% do acervo do Arquivo Militar, no século XIX, era composto por aqueles itens, sendo o restante integrado em pouco mais de $90 \%$ por plantas e projetos. Em segundo lugar, pode-se observar, nesse rol, que a participação de documentos anteriores ao século XIX é minoritária, compondo apenas cerca de $10 \%$ do total do mesmo

Anos 90, Porto Alegre, v. 11, n. 19/20, p.299-318, jan./dez. 2004 
A Carta Niemeyer de 1846 e as condições de leitura...

acervo. Assim, conclui-se que, no século XIX, embora a produção cartográfica do Exército tenha sido importante, compreendida enquanto tal o somatório dos esforços de seus oficiais engenheiros, do Arquivo Militar e da Oficina Litográfica, ela se concentrou mais na elaboração de plantas e projetos.

Em terceiro lugar, a produção do Exército apresentou mais atividade entre 1850 e 1889, com seu apogeu entre 1860 e 1889, data a partir da qual ela foi dividida por províncias, decrescendo entre cinco e até sete vezes. Portanto, dada a natureza dessa produção e se entendermos que sua origem, a criação do Arquivo Militar, foi a necessidade de o Estado utilizar diretamente a produção cartográfica no esforço de governo, podemos deduzir que os seus objetos concentrassem os interesses da administração e os esforços para a centralização da autoridade. Em defesa dessa tese, observe-se que as províncias do Rio de Janeiro e do Rio Grande do Sul foram o foco da produção cartográfica do Exército, correspondendo, respectivamente, por $26 \%$ e $16 \%$ de todos os projetos e plantas, seguidas de longe pelas províncias da Bahia e do Pará, com 9\%.7

Em quarto lugar, constata-se que o esforço de composição e da produção em escala de vários dos mapas provinciais escapou do controle direto do processo externo e passou às mãos de particulares, como, por exemplo, no caso do Mapa da Província do Rio de Janeiro, que foi elaborado por Pedro de Alcântara Bellegarde e Conrado Jacob de Niemeyer em 1863, e dos mapas das províncias do Paraná, Espírito Santo e Santa Catarina, os quais foram impressos pelo Imperial Instituto Artístico, ou, ainda, de diversos outros mapas que comprovam a idéia de que a lucratividade do mercado litográfico permitiu que a iniciativa particular se dedicasse também à impressão e ao comércio de vários tipos de mapas, como, por exemplo, a Planta da Cidade do Rio de Janeiro, produzida por Steinmann em 1831, e o Mapa Geral do Império do Brasil, elaborado por J. H. Leonhart em 1851.

Portanto, se relacionarmos esses exemplos com as cifras anteriormente citadas e os problemas acerca da manutenção dos quadros do Arquivo Militar, confirma-se no Brasil tanto a tradição

Anos 90, Porto Alegre, v. 11, n. 19/20, p.299-318, jan./dez. 2004 


\section{Renato Amado Peixoto}

européia de descentralização da produção cartográfica de escala, como a constituição de um mercado capaz de suportar uma produção litográfica independente e em contato com o exterior, com a subseqüente necessidade de o processo externo adaptar-se às características do processo interno, o que resultou no esvaziamento das atribuições e funções do Arquivo Militar.

\section{A Carta de Niemeyer de 1846}

Na década de 1840, a consolidação da discussão do espaço nacional em teatros da narrativa bem definidos em torno do IHGB e da Secretaria dos Negócios Estrangeiros, a descentralização do processo externo e da produção cartográfica em escala e o esvaziamento das funções do Arquivo Militar fizeram com que a primeira Carta Geral do Brasil não nascesse a partir de uma iniciativa do Estado, mas de uma contribuição para o debate da narrativa territorial no IHGB. Construída por Conrado Jacob de Niemeyer durante os anos de 1842 a 1846, a Carta Corográfica do Império do Brasil estabeleceu padrões técnicos e estéticos que seriam endossados pelas Cartas Gerais posteriores e mapas parciais do território, condicionando assim o processo externo às interpretações e limitações do processo interno. Nesse sentido, a composição da Carta de 1846 envolveu um procedimento de escolha do padrão técnico que pode ser caracterizado em três níveis de apreensões do processo interno: o primeiro, do geral, relacionado à inserção no universo conhecido das representações cartográficas; o segundo, do particular, relacionado à escolha do repertório das tradições das experimentações do território; o terceiro, do conceitual, relacionado à divulgação e à consolidação das formas percebidas e extraídas da intuição. ${ }^{8}$

Assim, Niemeyer procurou inicialmente basear sua representação do território brasileiro sobre o que chamou de Mapa Geral, ou seja, o produto resultante da reunião dos traçados de duas cartas estrangeiras, a Carta da América Meridional, da casa editorial Arrowsmith, e a Carta da Costa Brasileira, do Almirante Roussin. Em seguida, esse Mapa Geral foi modificado e complementado

Anos 90, Porto Alegre, v. 11, n. 19/20, p.299-318, jan./dez. 2004 
A Carta Niemeyer de 1846 e as condições de leitura...

através da consulta a diversos mapas, roteiros, memórias e descrições, sendo que, entre este último tipo de corografias textuais, Niemeyer utilizou especialmente os trabalhos de Cerqueira e Silva (1883), Cunha Mattos (1874) e Aires de Casal (1943), no caso, segundo os trabalhos cartográficos acreditados no debate do IHGB e pela remissão ao cânone ali consagrado. Finalmente, os limites nacionais foram inscritos sobre o produto resultante segundo o Programa Geográfico, de Pinheiro, e a divisão das províncias, de acordo com a Corografia Brasílica, de Aires de Casal.

Já o processo de escolha do padrão estético derivou da decisão de se compor o Mapa Geral a partir da redução e transformação da sua base de dados a uma escala (1:3.000.000) que viabilizasse a composição da Carta Geral em quatro folhas iguais, de acordo com a maior capacidade de impressão da litografia mais bem aparelhada no Brasil naquele momento, a Litografia Rensburg, possibilitando assim que a Carta atingisse o tamanho de $1,50 \mathrm{~m}$ de altura por $1,50 \mathrm{~m}$ de largura. A decisão de orientar todo o projeto cartográfico da Carta de 1846 pelo tamanho da maior folha que fosse possível imprimir foi tomada por Niemeyer em função de três objetivos: primeiro, tornar certos detalhes distinguíveis em relação a outros e "dignos de atenção", especialmente aqueles relativos aos limites com o Paraguai; segundo, diminuir o problema dos erros, através do maior dimensionamento dos elementos geográficos, especialmente da hidrografia; terceiro, equiparar a representação cartográfica do espaço nacional às cartas de grande dimensão impressas na Europa (Instituto..., 1844, 1846; Carta..., 1924).

Quanto ao último objetivo, o modelo para Niemeyer eram justamente as grandes cartas gravadas pela casa editorial Arrowsmith, as quais chegavam a medir até dois metros de altura por um metro e quarenta de largura. ${ }^{9}$ Essas cartas eram também impressas em várias folhas e juntadas para formar o produto final, o qual se destinava a ser exposto emoldurado em grandes paredes, geralmente em órgãos públicos e escolas, diferente dos demais mapas, que simplesmente eram enrolados após a consulta. Portanto, o padrão estético inaugurado por Niemeyer buscava não apenas formatar e inserir o

Anos 90, Porto Alegre, v. 11, n. 19/20, p.299-318, jan./dez. 2004 


\section{Renato Amado Peixoto}

Estado brasileiro no espaço, mas ainda construir sua presença, centralidade e monumentalidade através da imposição de sua representação, produzindo um mediador que visava interagir nas relações do indivíduo com o meio social e que lhe seria imposto por um ordenamento das próprias relações entre ele e o Estado. ${ }^{10}$ As funções específicas desse mediador derivam das transformações culturais e tecnológicas do século XIX, que aumentaram a distinção entre criação e produçã $0^{11}$ ao dinamizar os processos de construção e operação da representação, possibilitando a sua constituição enquanto um produto do artifício, ou seja, como uma representação tornada ilimitadamente disponível e que adquiriu novas funções, justamente por essa característica adequar-se às estratégias do processo externo.

Finalmente, esse mediador é elaborado sobre as estratégias e táticas desenvolvidas na relação entre o processo externo e o processo interno, quando recebe a expressão de suas tensões através da inscrição ou da negação da inscriçãa $0^{12}$ de "alegorias" ou "representações simbólicas" como elementos estruturais dos mapas, aos quais também corresponde o condicionamento de sua criação e construção histórica. ${ }^{13}$ Assim, acreditamos que a interpretação semiológica e iconológica não deva ser utilizada isoladamente, mas entronizada em um método que ultrapasse os aspectos imediatos do mapa e dê conta dos processos de objetivação do ato de representação, sendo ainda capaz de permitir a utilização dos recursos levantados pela História da Cartografia tradicional. Em razão disso, sugerimos que a interpretação semiológica e iconológica dos produtos cartográficos pode se basear nos significados percebidos através do estudo das relações desenvolvidas entre o processo interno e o processo externo, bem como da compreensão de sua inserção no problema geral da forma cartográfica.

Como exemplos desse método, apontaremos três aspectos retirados da mesma Carta Niemeyer. Em primeiro lugar, nesse mapa, o meridiano que passa pela cidade do Rio de Janeiro é utilizado como origem de todo o sistema de coordenadas, distinguindo-se dos que eram utilizados usualmente, a saber, os meridianos de Paris

Anos 90, Porto Alegre, v. 11, n. 19/20, p.299-318, jan./dez. 2004 
A Carta Niemeyer de 1846 e as condições de leitura...

ou de Londres. Essa opção pode ser compreendida a partir da inserção da Carta Niemeyer no debate então travado no IHGB sobre a construção da Nação e da Nacionalidade, responsável também por selecionar, disponibilizar e legitimar os textos corográficos a partir dos quais se completou a composição do espaço inscrito na Carta Niemeyer.

Em segundo lugar, o destaque dado à divisão provincial pela utilização do colorido quase que a equipara à divisão internacional. Esse destaque pode ser entendido tanto pela ênfase com que o autor que serviu de base à divisão provincial, Manoel Ayres de Casal, trata da questão, quanto pela sobrevivência da questão regional ainda na década de 1840. Em outras cartas da mesma época, era comum que mapas menores ou mesmo desenhos fossem dispostos dentro do mapa principal ou ao redor dele, mas, na Carta Niemeyer, as plantas das capitais das províncias do Rio Grande do Sul, São Paulo, Rio de Janeiro, Minas Gerais, Bahia, Pernambuco, Maranhão e Pará e a planta da Corte verdadeiramente emolduram o Mapa do Brasil, evidenciando, portanto, a sobrevivência da questão regional em meio à construção do nacional.

Finalmente, utilizando o mesmo método, podemos compreender as distintas implicações sociais e políticas da inscrição do espaço através do estudo dos elementos utilizados para descrever o espaço e de sua comparação às representações que se fizeram em torno da construção da Nação, especialmente se considerarmos o binômio civilização x barbárie, conforme idealizado por Ilmar R. de Mattos (1999). Nesse caso, a Carta Niemeyer é prolífica em exemplos dessa representação, como: "Gentio Jacundá tratável e que fala a língua geral"; "Sertão ainda desconhecido e sem cultura"; "Terrenos inteiramente desconhecidos e ocupados por diversas tribos de índios selvagens que embaraçam a navegação fluvial" e "Paritins, Andiras, Araras, Mundrucus e outras nações - Em grande parte domesticados". 


\section{Renato Amado Peixoto}

\section{Conclusão}

Acreditamos que a compreensão dos limites e das possibilidades dos produtos cartográficos pode resultar na constituição destes enquanto recursos de grande valia para o ofício do historiador. Portanto, é necessário primeiramente compreender que a transformação dos processos e das práticas cartográficas constitui-se num problema em si mesmo, o qual, muitas vezes, não corresponde às intenções do pesquisador. Em segundo lugar, entendemos que a leitura dos mapas deve ser feita através da investigação das estratégias e táticas inerentes à sua composição, as quais incluem tanto o agenciamento das técnicas e das condições da escrita quanto a distribuição e atribuição de tarefas. Por último, entendemos que é necessário investigar a socialidade dessa composição tendo-se em vista que seu sujeito é também um sistema de relações entre os diversos estratos de sua escritura, e que sua escrita deve ser entendida no mesmo sentido.

Niemeyer Chart of 1846 and the reading conditions of cartographic materials Abstract. Niemeyer Chart, printed in 1846, was the first Brazilian General Chart and, through this, we intend to discuss the usage and reading conditions of cartographic products by historians, aiming at the same time, to define its limits and possibilities.

Keywords: Niemeyer Chart (1846). Cartographic products.

\section{Notas}

${ }^{1}$ Ver Guimarães (1988).

${ }^{2}$ No caso, Saber e Poder implicam-se mutuamente: não existiria relação de poder sem a constituição de um campo correlato de saber, assim como não existiria saber que não pressupusesse e constituísse relações de poder. Ver Harley (2001d, p.87, 2001e, p.37).

${ }^{3}$ Em relação à teoria da representação e correlata objetivação da Vontade, ver Schopenhauer (2003, cap. 2).

${ }^{4}$ A partir dos conceitos sugeridos por Derrida (2002, p.221-223) em sua leitura da obra de Freud.

Anos 90, Porto Alegre, v. 11, n. 19/20, p.299-318, jan./dez. 2004 


\section{A Carta Niemeyer de 1846 e as condições de leitura...}

${ }^{5} \mathrm{O}$ gênio é entendido, por Schopenhauer, como uma capacidade de conhecimento inata e que se encontra em diversos graus em todos os homens, o que pressupõe serem-lhe inerentes as habilidades da criatividade e do entendimento. Ver Schopenhauer (2003, p. 83-87).

${ }^{6}$ A respeito da influência dos estilos e da transmissão de padrões na cartografia manuscrita, ver Marques (1989, p. 87-97).

${ }^{7}$ Esses dados foram tabulados sobre a descrição pormenorizada do acervo que foi realizada por Cláudio Moreira Bento, pouco antes deste ser confiado ao Arquivo do Exército no Rio de Janeiro. Ver Bento (1985).

${ }^{8}$ Essa idéia origina-se da relação estabelecida por Schopenhauer entre a música, a realidade e os conceitos abstratos. Ver Schopenhauer (2001, \$52).

${ }^{9}$ Por exemplo, a carta de 1814 da América do Sul. Ver Arrowsmith (1814).

${ }^{10}$ Procuramos aqui adaptar a idéia de mediador de Abraham Moles (1986, p.1219), desenvolvida por esse autor para explicar as transformações da representação e de sua operação nas sociedades de consumo.

${ }^{11}$ Essa distinção pode ser pensada também a partir da teorização de Abraham Moles (1986, p.15-22), no sentido de que o processo de criação seria correlato à idéia de introdução, invenção e produção do ato de copiar, reproduzir, e que as transformações do século XIX teriam dinamizado a produção, substituindo a criação por uma cadeia operatória, mas entendendo-se esta como um desdobramento da operação da representação em vários níveis visando à reprodução em escala e não necessariamente como parte de um processo de alienação.

${ }^{12}$ Essa idéia corresponde aproximadamente ao que Harley denomina de "Silêncios" (Silences): para esse autor, o espaço vazio nos mapas estaria ligado a um discurso político e à legitimidade de seu status, enquanto que, em nossa idéia da negação da inscrição, o "Silêncio" não corresponderia a um vazio, mas a um espaço preenchido por uma continuação ou um desdobramento daquele discurso. Ver (2001d, p. 99-100).

${ }^{13}$ Arthur Schopenhauer (2001, \50) identifica a historicidade das "alegorias" e "representações simbólicas" como parte mesmo do problema da compreensão da Representação.

\section{Referências}

ARROWSMITH, Aaron. South America. London: A. Arrowsmith, 1814.

BELLEGARDE, Pedro de Alcântara; NIEMEYER, Conrado Jacob de. Carta Corográfica da Provincia do Rio de Janeiro (Relatório). Rio de Janeiro: Tipografia do Instituto Artístico, 1863.

Anos 90, Porto Alegre, v. 11, n. 19/20, p.299-318, jan./dez. 2004 


\section{Renato Amado Peixoto}

BENTO, Cláudio Moreira. Cartografia histórica do Exército. Revista do Instituto Histórico e Geográfico Brasileiro, v. 41, abr./jun. 1985.

BRITO, Pedro Torquato Xavier de. História da litografia. Rio de Janeiro: IHGB, s/d. Lata 26, Pasta 1.

BRITO, Pedro Torquato Xavier de. Notícia acerca da introdução da arte litográfica e do estado de perfeição em que se acha a cartografia no Império do Brasil. Revista do Instituto Histórico e Geográfico Brasileiro, v. 41, tomo 33, parte II, 1870.

CARTA de Jacob de Niemeyer para o Visconde de São Leopoldo em 20/9/1843. In: PAUWELS, Geraldo José. Algumas notas sobre a gênese dos números para as áreas do Brasil e seus estados. Porto Alegre: Tipografia do Centro, 1924. p. 7-8.

CASAL, Manoel Ayres de. Corografia brasílica ou relação bistórico-geográfica do Brasil. São Paulo: E. e H. Laemmert, 1817; Edições Cultural, 1943. II v.

DERRIDA, Jacques. Freud e a cena da escritura. In: A escritura e a diferença. São Paulo: Perspectiva, 2002.

GUIMARÃES, Manoel Luiz Salgado. Nação e civilização nos trópicos: o Instituto Histórico e Geográfico Brasileiro e o projeto de uma história nacional. Estudos Históricos, Rio de Janeiro, v.1, n.1, p. 5-27, 1988.

HARLEY, J. B. Deconstructing the map. In: The new nature of maps: essays in the History of Cartography. Baltimore: The John Hopkins University Press, 2001a.

Maps, knowledge and power. In: Baltimore: The John Hopkins University Press, 2001b.

Power and legitimation in the English geographical atlases of the eighteenth century In. Baltimore: The John Hopkins University Press, 2001c.

Silences and secrecy - The hidden agenda of cartography in early Europe. In. Baltimore: The John Hopkins University Press, 2001d.

Text and context in the interpretation in early maps. . In. Baltimore: The John Hopkins University Press, 2001e.

INSTITUTO HISTÓRICO E GEOGRÁFICO BRASILEIRO. Carta de Conrado Jacob de Niemeyer ao IHGB oferecendo a Carta Corográfica do Império Brasileiro. Lata 510, Pasta 5, 1846.

Nota de Conrado Jacob de Niemeyer, dizendo estar quase pronta a carta corográfica do Império do Brasil. Lata 142, Pasta 49, 1844.

MARQUES, Alfredo Pinheiro. The dating of the oldest Portuguese charts. Imago Mundi, 41, p. 87-97, 1989.

Anos 90, Porto Alegre, v. 11, n. 19/20, p.299-318, jan./dez. 2004 


\section{A Carta Niemeyer de 1846 e as condições de leitura...}

MATOS, Raimundo José da Cunha. Corografia histórica da Província de Goiás. Revista do Instituto Histórico e Geográfico Brasileiro, v. 37, tomo 48, 1874.

MATTOS, Ilmar Rohloff. O tempo saquarema: a formação do Estado imperial. 4. ed. Rio de Janeiro: ACCESS, 1999.

MOLES, Abraham. O kitsch. São Paulo: Perspectiva, 1986.

MUKERJI, Chandra. A new world picture: maps as capital goods for the modern world system. In: From graven images: patterns of modern materialism. New York: Columbia University Press, 1983a.

Pictorial prints and the growth of consumerism: class and cosmopolitanism in early modern culture. In. New York: Columbia University Press, 1983b.

PANOFSKY, Erwin. Iconografia e iconologia: uma introdução ao estudo da arte da Renascença. In: Significado nas artes visuais. São Paulo: Perspectiva, 1976.

PEIXOTO, Renato Amado. A máscara da medusa: a construção do espaço nacional brasileiro através das corografias e da cartografia no século XIX. 2005. Tese (Doutorado) - Universidade Federal do Rio de Janeiro, 2005.

Mapeando o vazio: as percepções do espaço nacional nas cartas gerais. In: SIMPÓSIO NACIONAL DE HISTÓRIA, XXII, São Paulo, 2003. Anais Eletrônicos do... São Paulo: ANPUH, 2003. 1 CD-ROM.

SCHOPENHAUER, Arthur. A metafísica do belo. São Paulo: Editora Unesp, 2003. 2001.

O Mundo como vontade e representação. Rio de Janeiro: Contraponto,

SILVA, Ignacio Accioli de Cerqueira e. Corografia paraense ou descrição física, bistórica e política da Província do Grão-Pará. Salvador: Tipografia do Diário, 1833

VERNER, Coolie. Copperplate printing. In: WOODWARD, David. Five centuries of map printing. Chicago: University of Chicago Press, 1975.

Anos 90, Porto Alegre, v. 11, n. 19/20, p.299-318, jan./dez. 2004 